\title{
Los tratados bilaterales de protección de inversiones y su sometimiento a los derechos humanos y un breve excursus para el caso colombiano
}

\author{
The bilateral agreement trades and the subjection to the human rights \\ and a brief excursus of the Colombian case \\ Os tratados bilaterais de proteção de investimentos e a sua submissão \\ aos direitos humanos e um breve excursus para o caso colombiano
}

\author{
JuAN Felipe SOlÓRZANo Quintero*
}

FECHA DE RECEPCIÓN: 7 DE NOVIEMBRE DE 2016. FeCHA DE ACEPTACIÓN: 1 DE MARZO DE 2017

Para citar este artículo: Solórzano, J. F. (2017). Los tratados bilaterales de protección de inversiones y su sometimiento a los derechos humanos y un breve excursus para el caso colombiano. Estudios Socio-Jurídicos, 19(2), 223-258. Doi: xxxx

\section{RESUMEN}

Este escrito pretende mostrar de forma introductoria la obligación existente en materia de derecho internacional de inversiones de garantizar los derechos de la persona. Debemos reconocer que el Estado no es el único actor, aquel se ha visto transformado y hoy en día muchas de sus funciones y atributos fueron cedidos a favor de organizaciones internacionales, que en principio permiten hacer frente a las posibles vulneraciones de derechos de la persona. No obstante, en materia del derecho internacional de inversiones, se requiere un reforzamiento de estas garantías. En este sentido, pretendemos hacer notar algunos problemas que existen en lo referente a los tratados bilaterales de protección de inversiones y que requieren una transformación para estar acorde con la protección del individuo.

Palabras clave: Derechos humanos, derechos sociales económicos y culturales, derecho internacional de inversiones, pérdida de soberanía, transformación del Estado, tratados bilaterales de protección de inversiones.

* Abogado Magíster en Derecho Administrativo de la Universidad Colegio Mayor de Nuestra Señora del Rosario y doctor de la Universidad de Salamanca. Investigador invitado del Max-Planck-Institut für ausländisches öffentliches Recht und Völkerrecht y profesor vinculado al proyecto FCSH1701T1002 Grupo de Investigación en Justicia Global de la Universidad Tecnológica de Bolívar. ORCID ID: 0000-0002-5260-6464. Correo electrónico juansolorzano@usal. es; juanfelipe06@hotmail.com 


\section{ABSTRACT}

This paper shows the obligation within the international investment law to guarantee the rights of the person. Therefor we must be aware that the State is not the only actor, considering the fact that the state systems have been changing and their functions and certain attributes have been transferred to international organizations which can cope with the violations of rights of the person in a more effective way. Nevertheless, it is important to strengthen these guarantees within the international investment law. In this context, we will show some problems regarding the bilateral investment trades, as well as possible changes which allow a better protection of the individuals.

Keywords: Human rights, economic and cultural social rights, international law of investments, loss of sovereignty, transformation of the State, bilateral investment trades

\section{RESUMO}

Este escrito pretende mostrar de forma introdutória a obrigação existente em matéria de direitos internacional de investimentos de garantir os direitos da pessoa. Devemos reconhecer que o Estado não é o único ator, aquele se tem visto transformado e atualmente muitas das suas funções e atributos foram cedidos a favor de organizações internacionais, que em princípio permitem fazer frente às possíveis vulnerações de direitos da pessoa. No entanto, em matéria do direito internacional de investimentos, se requere um reforçamento destas garantias. Neste sentido, pretendemos fazer notar alguns problemas que existem no referente aos tratados bilaterais de proteção de investimentos e que requerem uma transformação para estar acorde com a proteção do indivíduo.

Palavras-chave: Direitos humanos, direitos sociais económicos e culturais, direito internacional de investimentos, perda de soberania, transformação do Estado, tratados bilaterais de proteção de investimentos. 


\section{Introducción}

El propósito de este trabajo es mostrar el distanciamiento entre el derecho internacional de inversiones y la protección de los Derechos Humanos y su necesidad de generar un acercamiento entre ellos. De un lado, se generó una cesión de soberanía por parte de los Estados que tuvo, presuntamente, como uno de sus propósitos generar mejores instrumentos internacionales para la protección de los derechos de las personas, particularmente de aquellos individuos que se encuentran en un grado de vulnerabilidad latente (Von Bogdandy, 2011). De otra parte, en la actualidad existe la posibilidad que el derecho internacional de inversiones transgreda los derechos humanos y, en conexión, los derechos sociales, económicos y culturales, ya que existe un fraccionamiento al interior del derecho internacional que en ocasiones hace que se contrapongan (Bohoslavsky \& Bautista, 2016; Koskenniem, 2006; Petersmann, 2009). Esto crea un escenario que a la luz de la protección de la dignidad es absolutamente inaceptable, ya que consideramos que este principio es el fundamento del ordenamiento jurídico tanto nacional como internacional ${ }^{1}$. En este sentido todas las normas jurídicas en principio deben tener como norte la protección de la persona, o al menos contar con herramientas que permitan su reivindicación.

En este sentido, para que exista una plena garantía de los derechos del individuo se hace necesaria la intervención asidua de las autoridades públicas (Von Bogdandy, 2014), partiendo de la voluntad legislativa hasta llegar a la adopción del presupuesto y de políticas públicas pendientes de la realización de planes que permitan la aplicación de estos derechos.

Si bien en el plano de los derechos (fundamentales y humanos) se gestó un gran avance hacia la protección y primacía de la persona, en el ámbito económico, como es obvio, se pretendía la protección de los mercados y el mayor rendimiento económico, lo cual se vio reforzado con las crisis a las que se vio enfrentado el modelo de Estado actual (De Cabo Martín, 2006). De lo anterior se desprende un escenario de oposición en el cual muchos de los intereses del mercado se contraponen con (2016)

Respecto a nuestra posición frente al principio de dignidad véase Solórzano Quintero 
los de los derechos del individuo, como ejemplo tenemos las garantías laborales, el pago de impuestos, el establecimiento y cumplimiento de unos parámetros protectores de la persona entre otros.

La situación descrita pone al Estado en una especie de encrucijada. De un lado, debe proteger los derechos de las personas, en virtud de su obligación constitucional e internacional que tiene. De otro lado, debe respetar y cumplir los pactos internacionales que permiten la inversión y el desarrollo económico al país, es el caso de las inversiones extranjeras. Frente a esta última situación Bohoslavsky \& Bautista (2016) manifiestan que el Estado debe cumplir con los tratados de inversiones que en ocasiones no se compadecen con la protección de los derechos, por lo que no son salvaguardados, y en cambio se deterioran poco a poco sin lugar a reivindicación alguna.

Para desarrollar este trabajo, en primer lugar, analizaremos algunos aspectos de las transformaciones del modelo de Estado y cómo a partir de la crisis actual este ha cambiado. A partir de esto, veremos cómo el derecho internacional público es una herramienta que puede servir para la protección de los derechos humanos. No obstante, en materia económica esta protección a los derechos no se ve tan clara. Es así como estudiaremos el caso de los tratados bilaterales de protección de inversiones y su enfrentamiento con los derechos humanos, observando algunas soluciones que la doctrina ha elaborado. Seguidamente, veremos brevemente el caso colombiano y cómo a través de la toma de decisiones y en aras de garantizar los derechos, el Estado puede entrar en un escenario de enfrentamiento con los derechos de los inversores. Finalmente, concluiremos que existen teorías que servirían para subsanar esta colisión, como es la desarrollada en el Instituto Max Planck de derecho público comparado y derecho internacional denominada Ius Constitutionale Commune en América Latina, la cual da herramientas para una protección efectiva de los derechos humanos. Además, permite el diálogo entre los jueces internacionales, lo cual redundará en que los árbitros generen una comunicación bidireccional que permita tener en cuenta los tratados en materia de derechos humanos. 


\section{La transformación del Estado en la dinámica internacional}

El Estado determina la forma en que el individuo y los poderes públicos se van a relacionar. En consecuencia, las Constituciones establecen la forma o manera de organización institucional, pero también los valores, los fines, los mandatos y los derechos que deben ser garantizados por el Estado (De Vergottini, 2004).

En este sentido, al ser el modelo de Estado el que determina las relaciones existentes entre este y el individuo, no se puede afirmar que el modelo de Estado es estático. De manera que se ha visto enfrentado a cumplir con ciertas exigencias que, en palabras de De Vergottini (2004), son denominadas finalidades, objetivos que se fijan en el quehacer de los órganos constitucionales. Hoy en día nuestras constituciones agrupan el postulado social, el democrático y el de Derecho que no deben entenderse de manera aislada. Siguiendo a García Pelayo (1989) deben concebirse de forma armónica sin que prevalezca o se imponga uno sobre el resto. De esta forma se aseguraría el cumplimiento de los fines del Estado que se concretan en la protección del individuo y en la garantía de la dignidad humana.

Ahora bien, el actual modelo de Estado se enfrenta a un escenario en el que muchos de sus postulados son transgredidos o se están viendo transformados. Debemos empezar por manifestar que el modelo del Estado social y democrático de Derecho desde antes que cobrara carta de naturaleza fue objeto de cuestionamientos. Así lo demuestra el debate que surgió en Alemania respecto del carácter jurídico constitucional del Estado social y su compatibilidad con el Estado de Derecho².

Aunado a lo anterior el modelo de Estado se ha enfrentado a profundas crisis que han puesto en entredicho su vigencia. La primera de ellas se originó en los años setenta (Carmona Cuenca, 2000) y la segunda tiene lugar en la actualidad. Hay sectores de la doctrina que han demostrado la constante erosión en la que está sometido el postulado social. $\mathrm{Al}$ respecto, De Cabo Martín (2006) sostiene que existe un deterioro

2 Respecto del debate que suscito la incorporación del postulado social en la constitución véase (Abendroth, 1973; Carmona Cuenca, 2000; Forsthoff, 1886; León Alomso, 2009) 
del principio de supremacía de la Constitución a favor de los intereses del capitalismo. Esto ha supuesto para el autor el desmantelamiento del Estado social y, como derivación de esto, la desprotección del individuo (De Cabo Martín, 2016).

Estas crisis han tenido unos efectos, que son el cambio de la política pública económica, la retirada progresiva de las actividades que en otrora ejercía el Estado, la contractualización, la desregulación y la cesión de soberanía. En esta última centraremos nuestro estudio, sin desconocer la transcendencia y relevancia de las otras consecuencias.

\subsection{La cesión de soberanía por parte de los Estados y el fin de la protección de los derechos humanos}

Una consecuencia de la crisis, como lo mencionamos, es la cesión de soberanía por parte de los Estados. Esto ha repercutido en la concepción del Estado. Expresa Serna de la Garza (2014) que en la época actual la globalización es uno de los principales factores que hacen que la concepción del Estado-nación deba readecuarse a las nuevas demandas de la sociedad y de la economía. Al respecto, conceptos tradicionales como el de soberanía vienen a ser debatidos y cuestionados en su concepción tradicional ya que se tornan de cierta manera insuficientes $\mathrm{u}$ obsoletos para explicar la nueva dinámica del Estado.

En otrora el Estado detentaba un poder absoluto que le permitía auto-determinarse a través del cumplimiento del ordenamiento jurídico constitucional y es a través de este último que se lograba la protección efectiva de la persona (Balbuena Cisneros, Estrada, \& Pisarello Prados, 2000). Sin embargo, vemos que el Estado no pudo satisfacer de manera efectiva todos los postulados y anhelos que se preceptúan en la Constitución. Así, y por citar algún ejemplo, en Latinoamérica los índices de pobreza y vulnerabilidad de pobreza están alrededor del 50\% (Naciones Unidas, 2016). Además, existe una precariedad en la exigibilidad de los derechos sociales (Balbuena Cisneros et ál., 2000).

Estas cuestiones han llevado ante la dinámica de la sociedad que las relaciones dejen de ser exclusivamente domésticas y traspasen las fronteras, creándose fenómenos como inmigraciones masivas o expansión de los mercados, entre otros. Todo esto ha generado un fenómeno global 
que ha permitido la creación de organizaciones supranacionales e internacionales que han empezado a ejercer de manera conjunta las funciones que eran exclusivas del Estado. Este tipo de fenómenos ha llevado a que el derecho público cambie de manera radical (Von Bogdandy, 2014). De lo anterior, podemos inferir que nos encontramos ante un escenario de "descentralización del ejercicio del poder público en múltiples esferas, que escapan al control de los órganos estatales" (Torres Pérez, 2012, p. 121). Así las cosas, la soberanía no puede entenderse como un poder absoluto del Estado. Si bien el Estado no ha perdido sus capacidades regulatorias y operacionales y sigue siendo un actor fundamental en el ámbito interno (Serna de la Garza, 2014), también es cierto que su autonomía en la decisión de políticas públicas ha sido menoscabada a favor de organizaciones supra o internacionales. Esto lleva a pensar que el control absoluto del ejercicio del poder se transforma y se comparte (Torres Pérez, 2012).

Teniendo en cuenta estas premisas consideraríamos que en el actual régimen mundial el postulado democrático, el social y el de Derecho se encontrarían en principio salvaguardados, ya que existe un conjunto de organizaciones internacionales y de Estados que reforzarían el cumplimiento de cada uno de estos principios. Inclusive se habla de una estatalidad abierta (Offene Staatlichkeit) en Europa y en América Latina, que permite, en palabras de Morales Antoniazzi, el examen de la configuración del

[...] constitucionalismo garantista de los derechos humanos y de la integración, no sólo como fin del Estado a favor de la cooperación internacional, sino como miembro de la comunidad internacional, que se somete a ella, en la evolución de un orden jurídico respetuoso de la dignidad humana (2014, p. 234).

En este sentido el principio de dignidad deviene en el fundamento del orden jurídico interno y externo y son los derechos de la persona los que dan la razón de ser de los poderes públicos.

Sin embargo, frente a este panorama normativo observamos que la protección de los derechos de la persona debe reforzarse aún más. Si bien la evolución del Estado como mencionamos anteriormente, la del derecho público (Häberle, 2008) y del derecho internacional (Gros 
Espiell, 2003) han generado una serie de garantías que buscan proteger la dignidad de la persona, estas no son suficientes ya que cada día la persona se enfrenta a nuevos retos que hacen que el derecho avance hacía la protección integral del individuo.

Uno de estos retos es la globalización ${ }^{3}$ que no implica per se la garantía de los derechos de las personas, es decir, para su salvaguarda se hace necesario que las autoridades públicas ejerzan mecanismos tendientes a instrumentalizar herramientas que permitan la protección del individuo. Por el contrario, y como sostiene Pisarello Prados (2000), la nueva dinámica mundial puede llevar a hablar de una protección de los derechos de los inversores y de los grandes propietarios internacionales, sin que sea extensivo al resto de las personas. En este orden de ideas De Lucas Martín (1998) pone de manifiesto la actual precariedad en la satisfacción de los derechos particularmente a los sociales.

Es cierto que la apertura mundial ha permitido la creación de organismos internacionales protectores de los Derechos Humanos, los cuales son esperanzadores para la garantía y la primacía de la dignidad de la persona. Encontramos entonces, por ejemplo, la Corte Interamericana de Derechos Humanos en Latinoamérica o el Tribunal Europeo de Derechos Humanos. Pero estas instituciones no son suficientes, sus competencias escapan de actos que a todas luces son violatorios del régimen de los derechos humanos, incluso los Estados no pueden dirimir en principio estos asuntos en la jurisdicción doméstica, lo cual deja a este tipo de hechos en una especie de limbo.

\subsection{Protección de inversiones extranjeras versus la garantía de los derechos sociales}

La nueva dinámica internacional ha generado que las estructuras estatales tengan una apertura a los mercados internacionales (López-Ayllón, 1997). Esto ha supuesto que el Estado se haya visto obligado a cambiar su estructura orgánica y normativa por las constantes presiones de países económicamente más fuertes. Los países latinoamericanos, por ejemplo,

3 Respecto de la definición de globalización y sus consecuencias véase (Beck, 1998). 
se sometieron a la implantación de una política económica de liberalización, la venta de empresas públicas y la desregulación (Zamora, 1997).

Como muestra de este fenómeno Zamora (1997) expresa la gran influencia de Estados Unidos en Latinoamérica respecto a la adopción de políticas neo-liberales y de modelos propios del sistema jurídico estadounidense. Al respecto Pisarello Prados (2000) pone presente que la globalización pretende "legitimar ex post la expansión y hegemonía militar, cultural y económica de ciertas potencias mundiales y de macropoderes privados a ellas vinculados" (p. 25). Este proceso deviene en que los países más débiles se ven en cierta manera obligados a adoptar medidas legislativas determinadas por países económicamente fuertes (Zamora, 1997).

Así las cosas, y teniendo en cuenta las consecuencias de la globalización, creemos que las funciones del Estado dirigidas a la garantía y protección de los postulados constitucionales cada vez se ven más difíciles de conseguir, ya que otro tipo de intereses diferentes a la garantía de los derechos de la persona entran en juego (verbigracia, intereses económicos). Así pues, en lo que respecta a la consecución de los derechos sociales al someterse el Estado a una desestatización, la prestación de servicios básicos como educación, salud y pensiones tiende a quedar en manos de privados cuyo objetivo principal es obtener un beneficio económico. En consecuencia, estos servicios pueden verse afectados en su calidad y cobertura, lo cual atenta directamente con el principio de dignidad.

El Estado no sólo está perdiendo su poder de decisión política y de regulación frente a organizaciones supraestatales o internacionales, hay también presiones de empresas transnacionales o Estados que generan presiones a fin de adaptar por ejemplo algún tipo de legislación a sus intereses. Así, en los últimos años las grandes corporaciones han detentado el control económico mundial, como en su momento Cassese (2002) evidenció que, de los cien organismos más importantes económicamente del mundo, 51 eran empresas y 49, Estados. Recientemente, el periódico El País (Pozzi, 2016), reveló que los ingresos de las diez empresas más importantes del mundo son comparables a la sumatoria del producto interno bruto de 180 países. Lo anterior demuestra el poderío que adquieren las multinacionales, el cual no sólo es económico, sino que puede trasladarse a ámbitos políticos y sociales. 
Como consecuencia del aumento en su capacidad económica, las transnacionales han llevado a determinar la legislación al interior de los Estados, demandándoles la continua adaptación del ordenamiento jurídico a los intereses privados bajo la continua amenaza de realizar sus inversiones en otro Estado que este abierto a incorporar las reformas que solicitan (Mir Puigpelat, 2004). Este fenómeno hace que los países adapten sus legislaciones con el objetivo de mantener la inversión. Esto ha implicado que los Estados hagan un recorte progresivo de derechos de tipo social, como son las prestaciones laborales o de protección del medio ambiente, todo con el propósito que las grandes empresas puedan ejercer su actividad sin problema alguno y con la mayor cantidad de ganancias (Mir Puigpelat, 2004).

Aparte de la gran influencia al interior del Estado por parte de las empresas multinacionales, a nivel internacional se han generado instrumentos que permiten que este tipo de sociedades inviertan con relativa seguridad en un país. Hacemos alusión a los tratados bilaterales de protección de inversiones (TBPI) ${ }^{4}$ que otorgan una serie de derechos a los eventuales inversores de los Estados suscriptores, a saber "tratamiento justo y equitativo, la plena protección y seguridad, el principio de no discriminación, la cláusula de la nación más favorecida, la protección del inversor frente a la expropiación y el compromiso de permitir la libre transferencia de rentas" (Fernández Masía, 2013). El otorgamiento de estas garantías y derechos en principio se dan para promover la inversión internacional y el crecimiento económico.

Adicionalmente, en los TBPI se incluyen cláusulas o disposiciones referentes a la solución de controversias. Las diferencias serán resueltas a través del arbitraje internacional de inversiones. Este último, es una

modalidad de arbitraje [...] que se plantea como el mecanismo de resolución de las posibles controversias que se puedan producir entre un Estado receptor de una inversión y un inversionista de otro Estado, siempre y cuando exista un Tratado internacional de inversión suscrito 
entre el referido Estado y el Estado de la nacionalidad del inversionista (Navarro Rodríguez, 2016, p. 90).

Los arbitrajes se llevarán en su mayoría ante el Centro Internacional de Arreglo de Diferencias Relativas a Inversiones (CIADI), la Cámara Internacional de Comercio, la Cámara de Comercio de Estocolmo o por la configuración de tribunales ad hoc (Fernández Rosas, 2009).

En lo referente al Convenio de Washington, por el cual se creó el CIADI y se adoptó un mecanismo de solución de controversias en materia de inversiones, debemos manifestar que tuvo su génesis por la voluntad de los países más desarrollados de crear herramientas que garantizaran la protección de las inversiones de sus ciudadanos en países con un menor desarrollo (Leturia, 2016)"title" : "La contribuci \u00f3n al desarrollo del Estado Receptor como requisito de la nocilu00f3n de inversilu00f3n: La experiencia de los palu00edses latinoamericanos", "type" : "chapter" \}, "uris" : [ "http://www.mendeley.com/documents/?uuid=9a3a708f1718-4a3a-91 fe-486f4544ab74" ] \} ], "mendeley" : \{ "formattedCitation" : "Leturia, 2016. Entonces, en principio la intención del derecho internacional de inversiones, o al menos en lo que respecta al CIADI, no fue la de salvaguardar los derechos de la persona, sino la protección de los inversores. Eso ha generado una serie de críticas constantes por parte de la doctrina que aboga por la protección de los derechos de la persona.

Debemos empezar por decir que este tipo de mecanismos de resolución de conflictos tiene un gran atractivo para los inversores ya que evitan someterse a la jurisdicción contenciosa administrativa, que se caracteriza en algunos Estados por ser demorada y parcializada. Este tipo de procedimientos se identifican por su celeridad y flexibilidad de normas aplicables. Adicionalmente otorgan seguridad jurídica al inversor de posibles cambios normativos y la presunta falta de neutralidad que se puede predicar de los tribunales internos (Navarro Rodríguez, 2016).

De lo descrito, vemos entonces el desplazamiento de la jurisdicción contenciosa administrativa y todas las prerrogativas con que cuenta el Estado en el proceso contencioso interno por una jurisdicción foránea que se regirá por el derecho privado. En particular el arbitraje de inversiones en alguna forma toma el arbitraje del comercio internacional como fuente de la cual bebe su procedimiento. Al respecto encontramos 
un primer problema, los asuntos referentes al Estado y la prestación de bienes y servicios no pueden verse desde un lado estrictamente privado, ya que existen intereses supremos que, en ocasiones, deben ser privilegiados sobre los intereses económicos como son el caso de la dignidad, la igualdad material, el interés general o los derechos humanos.

Con base en lo anterior, se puede inferir que los derechos humanos pueden quedar relegados a un segundo plano, por cuanto se olvida la posición especial que detenta el Estado. Esto no significa que condenemos a los tribunales de arbitraje y pretendamos volver a la doctrina Calvo ${ }^{5}$. Los TBPI y los tribunales de arbitramento ayudan a limitar la posibilidad de abuso del poder por parte del Estado, pero también deben de garantizar un sano equilibrio entre los intereses económicos y la garantía de los derechos humanos (Schill, 2016).

En segundo lugar, como sostiene Fernández Masiá (2013) las decisiones de los tribunales de arbitramento pueden afectar el poder normativo y regulatorio de los gobiernos en temas de políticas públicas referentes a la consolidación de derechos sociales, piénsese en el trabajo, la educación, la prestación de servicios públicos de energía, agua, gas o de salud. Igualmente, si la indemnización es excesiva puede afectar la economía en general del país o de una región específica, lo cual repercute de manera directa en la consolidación del postulado social, ya que para poder garantizarlo hacen falta recursos económicos que permitan poner en marcha políticas públicas que lo satisfagan. Respecto de lo anterior, es menester manifestar que algunos TBPI intentan proteger asuntos referidos al interés social, pero de manera exigua ya que sólo se enuncian sin hacer énfasis en cómo será su protección (un ejemplo puede ser el Acuerdo entre Colombia y el Reino Unido que en su artículo cuarto se menciona el interés social sin consagrar cómo se debe interpretar este concepto tan importante para el derecho constitucional). Del mismo modo se omite la garantía de los derechos de la persona, elemento esencial no sólo en 
el ámbito interno del Estado, sino también en el ámbito internacional (Schreuer \& Reiner, 2011).

Un tercer problema radica en las decisiones falladas por los tribunales de arbitramento que deben ser aplicadas de manera inmediata y por lo general no tienen un recurso de apelación (Artículo 53, Convenio CIADI) aunque eventualmente existe el recurso de revisión (Artículo 52, Convenio CIADI). De no cumplirse con un laudo el Estado queda expuesto a sanciones internacionales. Así lo demuestran las sanciones a las que se vio sometida la República de Argentina por parte de Estados Unidos al no dar cumplimiento a un fallo que resultó favorable a los intereses de empresas norteamericanas (Van Harten, 2008).

Otro problema que se debe hacer notar es que los árbitros que componen estos tribunales son terceros que no tienen relación con un Estado. Adicionalmente, su especialidad es el derecho comercial por lo que no tienen trato con materias referentes a derechos humanos (Jacob, 2010). Con todo tienen la capacidad de fallar sobre materias que pueden referirse al ámbito económico y social de un país, afectando los postulados constitucionales. Esto, a nuestro modo de ver, lesiona no sólo el postulado social, también ataca de forma directa el postulado democrático. Asimismo, la forma de selección de los árbitros al ser realizada tanto por los Estados como por la parte inversora puede poner entredicho la independencia y la imparcialidad en el fallo dentro de un procedimiento arbitral (Van Harten, 2010). Al respecto, para poner de presente este punto es menester citar a Fernández Masiá (2013) quien sostiene:

A la tendencia de que la designación de cada parte contendiente de los árbitros se realiza en función de que sean proclives a sus intereses, hemos de añadir que el sistema actual permite que las mismas personas puedan actuar como árbitros en algunos casos y como abogados en otros (p.13).

Hacen notar Navarro Rodríguez (2016) y Fernández Masiá (2013) otro inconveniente y es la confidencialidad u opacidad de los fallos y el no seguimiento de precedentes. Esto hace que el procedimiento de arbitramento no siga parámetros que brinden seguridad jurídica y transparencia. Al existir secretismo se puede dejar abierta la puerta a decisiones 
que no se basen en el derecho, sino que se basen en los intereses de empresas privadas. Respecto del CIADI debemos manifestar (Von Bogdandy \& Venzke, 2013, Von Bogdandy \& Venzke, 2016) que ha tratado de mejorar la transparencia en sus procedimientos, incluso se habla de un seguimiento de precedentes.

Luego de vistas las criticas observamos que los TBPI deben tener en cuenta los derechos humanos por dos razones. La primera tiene que ver con que los tratados de derecho internacional público deben interpretarse de manera sistemática, así lo consagra la Convención de Viena en su sección tercera. Es decir, dentro de un arbitramento se debería analizar no sólo la norma a interpretar (TBPI) sino, todas aquellas que estén ligadas al asunto en litigio (verbigracia, normas referentes a derechos humanos). La segunda es que el Estado es un ente público encargado de velar y proteger a los individuos. Por lo tanto, resulta erróneo implementar una jurisdicción alejada de la realidad en materia de derechos (humanos o fundamentales).

En nuestros días hablamos del fraccionamiento en el derecho internacional. Prieto Muñoz (2016) expresa que:

[...] a substantive expansion took place creating a new global legal configuration with no central institutional hierarchy of a political, administrative, or judicial kind. This normative/institutional phenomenon was conceptualised as the 'fragmentation of international law', with a focus on the increase in the number of branches of international law (e.g., human rights, international criminal law, international investment law, etc.) which was accompanied by the proliferation of adjudicative bodies. (p. 137).

Pese a este fenómeno, consideramos que la normatividad internacional (Convención de Viena de los Tratados) y la jurisprudencia internacional, particularmente la referida a derechos humanos, ha intentado unir el derecho internacional teniendo como fundamento a las personas y haciendo hincapié en la obligación de protección y salvaguarda por parte de los Estados (Dupuy, 2011).

Bohoslavsky \& Bautista (2016) ponen de manifiesto la sujeción de muchos de los países latinoamericanos a tratados regionales y universa- 
les en materia de derechos humanos, lo cual impone a los Estados una serie de obligaciones en la consecución, satisfacción y garantía de los derechos ${ }^{6}$. Entonces, resulta ilógico pensar que un Estado suscribe una serie de tratados en el marco del derecho internacional de inversiones y con esto se puede excusar del deber de protección de los derechos humanos que ha adquirido.

En relación con lo anterior, Bazán (2014) sostiene, respecto al sistema interamericano, que "el Estado parte de la CADH no solo tiene el aludido deber de adoptar las medidas de derecho interno, sino que además está obligado a asegurarse que estas sean efectivas, es decir, cumplidas en el orden jurídico interno" (p. 400).

En vista de lo anterior, si el Estado realiza un hecho que conculca los derechos humanos en cumplimiento de un TBPI, incurre en todo caso en responsabilidad. Así lo reconoció la Corte Interamericana de Derechos Humanos (CIDH), en el caso Garrido y Baigorria c. Argentina, fallado mediante sentencia de agosto 27 de 1998, en donde recuerda que al cometerse un "hecho ilícito imputable al Estado, surge responsabilidad internacional de éste por violación de una norma internacional" (párr. 40). La CIDH dejo claro que:

[...] la aplicación de acuerdos comerciales bilaterales no justifica el incumplimiento de las obligaciones estatales emanadas de la Convención Americana; por el contrario, su aplicación debe ser siempre compatible con la Convención Americana, tratado multilateral de derechos humanos dotado de especificidad propia, que genera derechos a favor de individuos y no depende enteramente de la reciprocidad de los Estados. (Comunidad Indígena Sawhoyamaza c. Paraguay, sentencia de marzo 29 de 2006, párr. 140).

Las sentencias citadas de la CIDH sirven para contrarrestar los argumentos de quienes dicen que el derecho internacional de inversiones y los derechos humanos son dos mundos contrapuestos. Por el contrario:

6 Respecto de la obligación de cumplimiento y observancia por parte de los poderes públicos en el sistema interamericano de derechos humanos véase Corte Interamericana de Derechos Humanos (2011), caso Gelman c. Uruguay, sentencias del 24 de febrero de 2011, párr. 239. Resolución de cumplimiento caso Gelman c. Uruguay, del 20 de marzo de 2013, párr. 72. 
se pone de manifiesto la necesidad de dialogo entre estas dos ramas del derecho.

Adicionalmente, y teniendo como base el principio de dignidad y su protección por parte de las autoridades públicas, nos es dable decir que este principio proviene de la naturaleza humana y le da estatus al hombre $\mathrm{y}$, por tenerlo, se generan una serie de derechos que son los que brindan una guía en la formación del ordenamiento y en el quehacer de las autoridades públicas. En palabras de Peces-Barba Martínez, la dignidad es un "[...] fundamento de la ética pública de la modernidad, como un prius de los valores políticos y jurídicos y de los principios que derivan de esos valores" (Peces Barba Martínez, 2003 p. 12).

Entonces, al fundamentarse el ordenamiento jurídico en el principio de dignidad las autoridades públicas deben en todo momento tener presente el concepto de persona. Esta obligación también se podría hacer extensiva a los tribunales de arbitramento que según Von Bogdandy (2014) son "autoridades públicas internacionales".

La propuesta en entender a la autoridad pública como la capacidad legal de determinar a otros y de reducir sus libertades, es decir, de configurar unilateralmente su situación jurídica de facto. Esta determinación puede, en primer lugar, llevarse a cabo por medio de actos jurídicamente vinculantes [...] Un acto es jurídicamente vinculante cuando modifica la situación jurídica de otro sujeto jurídico sobre todo cuando una acción contraria a ese acto es ilegal (Von Bogdandy, 2014, p.73).

De este modo, los tribunales de arbitramento tienen la capacidad de configurar una situación jurídica que vincule y obligue a un Estado a realizar determinada prestación con el objetivo de satisfacer lo estipulado en un laudo. El autor en cita además reconoce que este tipo de tribunales son verdaderos creadores de derecho internacional (Von Bogdandy $\mathcal{E}$ Venzke, 2011). Se puede inferir entonces, que los árbitros juegan un papel determinante en la escena jurídica pública internacional y estatal. A causa de esto deberían tener un papel garante del individuo y en consecuencia de sus derechos. Entonces, el derecho internacional no puede omitir los derechos humanos y aplicar exclusivamente los principios que impone el derecho internacional de inversiones (Dupuy, 2011). 
En este orden de cosas, tanto la doctrina como algunas organizaciones internacionales han establecido algunos mecanismos para tratar de solventar la situación. Así, la United Nations Conference on Trade and Development (UNCTAD) en el informe de 2015 pone de manifiesto la necesidad de ahondar en mecanismos que den la libertad de regular a los Estados con el propósito de satisfacer el interés general, ya que muchas veces los TBPI imponen limites que restringen el quehacer de los poderes públicos, lo cual afecta de manera grave la formulación de políticas públicas necesarias para la satisfacción de los derechos, principalmente los de carácter social (UNCTAD, 2015, pp. XVI y 30).

Por su parte Schill (2016) sostiene que, a la hora de analizar los tratados de inversiones, se debe hacer desde una perspectiva comparada, recurriendo a un análisis interdisciplinario enfocado al derecho constitucional y administrativo, teniendo como recursos los derechos humanos. En este sentido, bajo estos parámetros considera el autor que de esta manera el arbitraje internacional de inversiones se constituye en una especie de revisión judicial y administrativa, por cuanto le impone límites al ejercicio de las autoridades públicas.

Para que no haya lugar a controversia y a fin de contar con herramientas que hagan fácil la protección de los derechos humanos y los sociales, económicos y culturales, consideramos la necesidad de hacerse una expresa y extensa mención de éstos en los tratados, para que $a$ posteriori los árbitros se vean obligados a tener en cuenta estos derechos en sus laudos. No debemos perder de vista que de no agregarse expresamente se podría alegar una nulidad por exceso de poder, ya que se argumentaría que el árbitro fue más allá del mandato otorgado (KnollTudor, 2009)"title" : "The fair and equitable treatment Standardas and Human Rights norms", "type" : "chapter" \}, "uris" : [ "http://www.mendeley.com/documents/?uuid=fae95a 1 e-e11 e-4e3c-9a7b-f1 fdf693c701" ] \} ], "mendeley" : \{ "formattedCitation" : "(Knoll-Tudor, 2009.

De otro lado, Von Bogdandy \& Venzke (2011) ponen como elemento crucial en The International judicial lawmaking el uso de precedentes y de motivaciones, esto redundará en la seguridad jurídica así como la coherencia y consistencia de las decisiones. También lo hará en la garantía de la transparencia y la publicidad se lograría tener laudos más acordes con los intereses públicos. 
Por su parte, Lee (2013) pone de manifiesto que al interior de la UNCITRAL se están realizando esfuerzos para la incorporación de estándares de transparencia. Adicionalmente, el Alto Comisionado para los Derechos Humanos (2003) reitera la necesidad de promoción de mecanismos directos e indirectos que promuevan la responsabilidad social de las empresas.

La UNCTAD propone un sistema de apelación y un mecanismo de prevención de controversias. Otra parte de la doctrina aboga por la aplicación de un derecho administrativo internacional que permita la garantía de los postulados que se tienen en la jurisdicción (Cassese, 2002; Navarro Rodríguez, 2016) se refiere los amici curiae, figura aplicada dentro del CIADI, que pueden entrar a ser garantes en la protección internacional de los derechos humanos. Esto pone de presente que diferentes tipos de organizaciones como ONG pueden intervenir en el proceso y dar argumentos necesarios que determinen el sentido de un fallo en beneficio del postulado social (verbigracia, derechos relacionados con el ambiente o con condiciones laborales adecuadas). De cualquier modo, la intervención de los amici curice queda a la discreción del tribunal de arbitramento por lo cual no en todos los casos puede darse este tipo de asesoría y control de las decisiones arbitrales.

También, debemos manifestar que recientemente en las negociaciones del Acuerdo económico comercial y global entre Canadá y la Unión Europea se está contemplando la posibilidad de crear un tribunal semipermanente (art. 8.27) encargado de resolver las disputas referentes a inversiones junto con un tribunal de apelación (art. 8.28.3, art. 8.28.5 y 8.28.7) (Prieto \& Urueña, 2016). Esto con el fin de darle más legitimidad, coherencia y, en cierta forma, unidad de doctrina a las decisiones que se tomen (Consejo de la Unión Europea, 2016). Al respecto Prieto \& Urueña (2016) consideran que la creación de este tribunal crea un sistema paralelo de justicia en sistemas judiciales estatales relativamente eficientes, competentes e imparciales.

En fin, este tipo de propuestas denotan que los postulados constitucionales merecen la pena tomarlos más en serio por parte de la comunidad internacional. No se deben sacrificar los postulados constitucionales, por los que el ser humano ha tenido que luchar de forma constante, únicamente por beneficiar el interés de unos pocos. Si bien es cierto que los países en 
vía de desarrollo dependen de manera importante de las inversiones, no se les debe volver a lo que consideramos es una nueva forma de laissez faire. Para ello, como indica la UNCTAD, los Estados deben retomar el papel fiscal que tienen e imponer los tributos y la regulación que haga falta a las empresas inversoras. Por su parte, las empresas deberán tener una mayor conciencia y, en lo posible, evitar la elusión de impuestos que tanto daño hace a la inversión social de un país.

No se debe dejar de lado que los Estados tienen el deber de cumplir de manera estricta los tratados de derechos humanos. Por lo tanto, existe un interés superior que es la garantía de los derechos de las personas. $\mathrm{Al}$ incorporar los tratados que consagran derechos humanos se da un reforzamiento a la teoría del doble carácter de los derechos ${ }^{7}$, en el sentido que el aspecto objetivo y subjetivo de los derechos no sólo se dará exclusivamente en el ámbito interno, las relaciones internacionales deben caracterizarse también por un sometimiento a estos. En consecuencia, en las relaciones que se tengan con un inversor extranjero deben prevalecer los derechos humanos sobre el económico.

Respecto a lo mencionado Bohoslavsky \& Bautista (2011) sostienen que por medio del control de convencionalidad los jueces pueden no acatar un fallo que a todas luces vulnere los derechos ${ }^{8}$. Esto es en virtud del interés superior que tiene el Estado en la protección de los derechos humanos y también en lo referente a las garantías que debe otorgar para el ejercicio de los derechos sociales, económicos y culturales. Al respecto

Para garantizar la relevancia del principio de dignidad los derechos de la persona son el mecanismo por el cual se puede materializar. Así, estos últimos no sólo son el límite de la actuación de los poderes públicos, también devienen en la fuente inspiradora del quehacer público. De ahí que los derechos fundamentales tienen un doble carácter (Der Doppelcharakter der Grundrechte). El primero, que es subjetivo o de protección frente a los excesos del Estado y de los particulares. El segundo objetivo, en donde los derechos en conjunto demandan su aplicación en el ordenamiento en general. En este entendido León Alonso (2009) explica que entre las consecuencias de la vertiente objetiva existe un efecto de irradiación de los derechos fundamentales que obligan a todos los poderes a su observancia. Además, impone a los poderes públicos mantener una actitud activa en la consecución y protección de los derechos fundamentales.

8 " [...] los jueces y tribunales internos están sujetos al imperio de la ley y, por ello, están obligados a aplicar las disposiciones vigentes en el ordenamiento jurídico. Pero cuando un Estado ha ratificado un tratado internacional como la Convención Americana, sus jueces, como parte del aparato del Estado, también están sometidos a ella, lo que les obliga a velar porque los efectos de las disposiciones de la Convención no se vean mermadas por la aplicación de leyes contrarias a su objeto y fin". Corte Interamericana de Derechos Humanos (2006), caso Almonacid Arellano y otros c.. Chile, sentencia del 26 de septiembre de 2006, párr. 124. 
podemos traer a colación lo manifestado por la CIDH en el caso Las Palmeras c. Colombia, en sentencia del 6 de diciembre de 2001:

La Convención Americana es un tratado multilateral mediante el cual los Estados Partes se obligan a garantizar y a hacer efectivos los derechos y libertades previstos en ella y a cumplir con las reparaciones que se dispongan. [...] Este sistema consta de un nivel nacional que consiste en la obligación de cada Estado de garantizar los derechos y libertades previstos en la Convención y de sancionar las infracciones que se cometieren. Ahora bien, si un caso concreto no es solucionado en la etapa interna o nacional, la Convención prevé un nivel internacional [...] Pero, [...] la protección internacional es "coadyuvante o complementaria de la que ofrece el derecho interno de los Estados americanos" (párr. 33).

Aparte de lo anterior Bohoslavsky \& Bautista (2016) expresan la posibilidad que posteriormente, y ante la aplicación del control de convencionalidad, sería la Corte Internacional de Justicia la que clarificaría el asunto en virtud del artículo 64 de la Convención del CIADI por la cual se faculta a los Estados a consultar sobre su aplicación, "y en caso se tratará de obtener una respuesta sobre los alcances del artículo 42 de esa convención a las luz del Artículo 31.3.c de la Convención de Viena sobre el derecho de los tratados y la normas internacionales de los derechos humanos" (p. 698).

\section{Aumento de posibilidades de acudir ante el CIADI por parte del Estado colombiano}

Como lo mencionamos anteriormente, en la región hubo una gran influencia de los movimientos neoliberales que propugnaban por la reducción del Estado y por la apertura económica. Este proceso hizo que los países latinoamericanos adaptaran sus sistemas jurídicos a las necesidades y a las nuevas tendencias del comercio internacional. Prieto (2011) afirma que este fenómeno de adopción normativa repercutió en 
nuestra actual constitución', la cual tuvo una gran influencia de estos movimientos neoliberales.

Fruto de la apertura económica los Estados de Latinoamérica han venido suscribiendo diferentes TBPI. Esto ha generado una situación particular: en muchos de los casos adelantados ante el CIADI existe un número considerable de países pertenecientes a la región (UNCTAD, 2016). Concomitantemente, se ha generado la denuncia del convenio del CIADI por parte de Bolivia (3 de noviembre de 2007) y la posterior denuncia de seis TBPI, la denuncia de Ecuador del Convenio ( 7 de enero de 2010) y la ulterior terminación de diez TBPI y, finalmente, la denuncia de Venezuela realizada al Convenio en 2012 (Polanco Lazo, 2016).

Ahora bien, esta situación no se ha generalizado en la región. Por el contrario, como lo reconoce Polanco Lazo (2016), la mayoría de los Estados latinoamericanos han permanecido en la jurisdicción del CIADI incluyendo a Argentina, país con el mayor número de casos en la región. Esta permanencia ha llevado a la renegociación de muchos de los TBPI y a la introducción de diferentes tipos de cláusulas en las que se trata de no darle un mayor beneficio a un inversor extranjero del exigido por el derecho internacional. Bajo esta orbita el autor en cita pone de presente los tratados suscritos por Colombia en los cuales se establece que "los conceptos «trato justo y equitativo» $\mathrm{y}$ «protección y seguridad plenas» no requieren de trato adicional a aquel requerido bajo el mínimo estándar de trato a extranjeros de conformidad con el estándar del derecho internacional consuetudinario"10 (p. 68).

Adicionalmente, países latinoamericanos como Perú, Chile, Uruguay o Colombia establecen en sus TBPI que ante una medida tributaria que constituya expropiación, el inversionista deberá remitir su queja a las autoridades tributarias antes de entablar una demanda arbitral. Si en el término de seis meses la autoridad tributaria y el inversionista no llegan a ningún acuerdo, este último podrá seguir con el procedimiento de reso-

9 Respecto de la evolución y adopción de los TBPI respecto de la Constitución Política de Colombia véase (Prieto, 2011).

10 Polanco Lazo (2016) enuncia el TBPI Colombia- China (2008) art. 2(4); TBPI BLEUColombia art. 111 (4), TBPI Colombia-India (2009) art. 3(4), TBPI Colombia-Reino Unido (2010) art. 11 (4), TBPI Colombia-Singapur (2013) art 4(2), Tratado de Libre Comercio Colombia-Corea (2013) art 8.5, Tratado de Libre Comercio Colombia-Costa Rica (2013) art 12:4 y Tratado de Libre Comercio Colombia-Israel (2013) art 10.3. 
lución de disputas (véase TBPI Colombia-Suiza, 2006 y TBPI ColombiaPerú, 2007). Advertimos que también existen tratados como es el caso del Tratado de Colombia-España en que, pese a no haberse estipulado la medida anterior, se da el plazo de seis meses para que las partes logren llegar a un acuerdo antes de iniciar el procedimiento arbitral.

Estas medidas a nuestro modo de ver permiten en primer lugar tratar de arreglar internamente las diferencias entre el Estado y el inversor y, en caso de saber que no se va a llegar a ningún acuerdo, permiten iniciar con antelación la preparación de la defensa. La doctrina concuerda en que países como Chile, Colombia, México o Perú han tratado de generar un mayor control sobre los inversores en la negociación y renegociación de los TBPI.

El papel que ha tenido Colombia ha sido proactivo ya que no era un país del que se pudiera predicar su alta litigiosidad en virtud del derecho internacional de inversiones. Pero esta apertura ha traído una serie de retos a los cuales ha tenido que enfrentarse en estos últimos años. En la actualidad se presenta la posibilidad que Colombia acuda ante el CIADI por acciones tomadas por el Estado frente a inversionistas extranjeros, a saber:

1) La multinacional suiza Glencore pretende iniciar un arbitraje por la condena impuesta por la Contraloría General de la República a su filial Prodeco ante las presuntas irregularidades en la modificación del contrato de explotación de carbón, por lo que el ente de control ordenó la renegociación del contrato (El club de la pelea: Ola de demandas contra Colombia, 2016)

2) La multinacional Eco Oro Minerals alega demoras en la definición de los límites del páramo de Santurbán para su explotación (cabe mencionar que esta región es considerada de importancia ecológica). En este asunto se pretende utilizar el Tratado de Libre Comercio entre Colombia y Canadá argumentando el incumplimiento por parte del Estado colombiano de los compromisos pactados y, en consecuencia, el perjuicio económico para el inversor (Eco Oro Minerals Corp. v. Republic of Colombia, 2016)

3) Consigo Resourses (Canadá), Consigo Resourses (Colombia) y Tobie Mining and Energy Inc. (EE. UU) demandaron a Colombia porque 
no pudieron explotar la concesión de minería de oro en una región dentro del Vaupés, por cuanto el Estado la declaró parque natural. La suma que pretenden los demandantes es de US\$16500 millones ("El club de la pelea: Ola de demandas contra Colombia," 2016).

Los dos últimos casos tienen que ver con el derecho ambiental, que es muy importante en la actualidad, pero del cual no nos ocuparemos en este trabajo, por cuanto excede nuestro objeto de estudio. Sin embargo, es menester dejar anunciadas estas situaciones por su relevancia en la garantía de los derechos en general.

4) Gas Natural, empresa española, pretende iniciar una demanda arbitral, en virtud del TBPI entre España y Colombia. Esto si las autoridades colombianas no resuelven el problema de deuda acumulado por los clientes del servicio de electricidad que presta Electricaribe (empresa filial de la compañía española) que asciende a 1100 millones de euros ("Gas Natural reclama 1.100 millones al Gobierno colombiano por impagos," 2016).

5) Finalmente, el caso que nos interesa analizar es el referente a la declaración de interés público del medicamento Imatinib producido por la multinacional farmacéutica Novartis (Suiza), al considerar el Estado colombiano que los costos del fármaco no ofrecían condiciones de competencia.

Para empezar el análisis del caso es necesario comprender el concepto de salud, así sea de manera instrumental ${ }^{11}$. Según la Organización Mundial de la Salud (OMS) el Derecho a la salud es: "un estado de completo bienestar físico, mental y social, y no solamente la ausencia de afecciones o enfermedades". Y agrega, "el goce del grado máximo de salud que se pueda lograr es uno de los derechos fundamentales de todo ser humano" (Constitución de la Organización Mundial de la Salud, Preámbulo). Esta pretensión según León Alonso (2009) en nuestros días cobra mayor relevancia y como resultado se ha visto incorporado este derecho en la legislación nacional e internacional.

11 Respecto a la consagración del Derecho a la salud en la Declaración de los derechos humanos y en el Pacto internacional de los derechos sociales económicos y sociales véase (Monereo Pérez, 2014). 
Bajo este plano es evidente como la salud tiene estrecha relación con los derechos humanos y con la obligación que tiene el Estado de garantizar ciertos servicios para brindar unas condiciones de vida mínimamente dignas al individuo. El Pacto Internacional de Derechos Sociales, Económicos y Culturales preceptuó en su artículo 12 la obligación de los Estados de reconocer a toda persona el más alto nivel posible en su salud tanto física como mental. Como es de común conocimiento, para la protección de este derecho es necesaria la actividad permanente del Estado, situación que hace que en su prestación se desarrollen elementos programáticos propios del modelo social, ya que se deben invertir recursos económicos y hace falta la voluntad del legislador y del ejecutivo para su protección.

Dicho de otro modo, el derecho a la salud como lo afirma León Alonso "constituye un paradigma de la superación de las divergencias extremas que tradicionalmente se han establecido entre los derechos sociales y derechos fundamentales" (2009, p. 11). Así tiene un aspecto subjetivo al ser una garantía y un límite que es exigible a los poderes públicos y a la sociedad.

De otro lado, tiene una faceta objetiva. El Estado tiene el deber de establecer un "nivel máximo de salud que se pueda lograr", esto según la OMS implica "la reivindicación de que mediante un conjunto de mecanismos sociales - normas, instituciones, leyes y un entorno propicio- se pueda garantizar de la mejor manera el disfrute de este derecho" (2002, p. 9). Para la evaluación del respeto al derecho el Comité de Derechos Económicos, Sociales y Culturales (CDESC), en la Observación General 14 de 2000 (Observación general 14, 2000) estableció unos estándares que los Estados deben acatar, a saber: disponibilidad, accesibilidad, aceptabilidad y calidad. Entonces, es innegable que el derecho fundamental a la salud en su aspecto social requiere de la intervención del Estado para que este genere los instrumentos necesarios para llevar una vida digna. En virtud de lo anterior, el Estado puede intervenir a fin que los hechos que constituyan una presunta violación al derecho a la salud cesen.

La situación descrita en teoría parece que no tendría ninguna oposición. Sin embargo, debemos analizar el hecho ocurrido en Colombia a raíz de la Resolución 2475 del 14 de junio de 2016, por medio de la cual el Ministerio de Salud y Protección Social declaró la existencia de razones de interés público del medicamento Imatinib, empleado para 
tratar el cáncer mieloide crónico y otras formas de cáncer. En consecuencia, se solicitó a la Comisión Nacional de Precios de Medicamentos y Dispositivos Médicos someter al fármaco en mención "al régimen de control directo de precios usando una metodología general que regule las situaciones de interés público". Esto, en términos prácticos, significa que el Gobierno emitirá una licencia obligatoria que permitiría que otros laboratorios farmacéuticos produzcan el medicamento sin el consentimiento de Novartis, empresa que ostenta la titularidad de la patente del fármaco. La razón de esta resolución es la necesidad de reducción de los precios del medicamento, el cual es 198\% mayor en relación con los medicamentos que se producían en Colombia por otros competidores ${ }^{12}$.

Los motivos que tuvo el Gobierno colombiano para declarar este medicamento como de interés público fueron, en primer lugar, el derecho que tienen las personas a la salud. En segundo lugar, la sostenibilidad del sistema general de salud ya que cierta parte del costo del medicamento es asumido por el Estado. Al respecto cabe mencionar que a través de la asistente del director general de la OMS para los sistemas de salud e innovación se manifestó la incorporación a partir de 2015 del medicamento Imatinib en la lista de medicamentos esenciales. Aunado a ello, sostuvo la posibilidad de expedir una licencia obligatoria con miras a garantizar el pleno acceso a este medicamento que combate el cáncer. Del mismo modo enfatizó el objetivo de la OMS de promover mecanismos para luchar con este tipo de enfermedades por lo que la organización se muestra de acuerdo en las medidas tomadas por Colombia, resaltando el rechazo de la farmacéutica (Novartis) en llegar a un acuerdo en el cual se puedan negociar los términos justos en donde se garantice el derecho a la salud y el derecho a la propiedad intelectual (patente).

Lo cierto es que las medidas tomadas por el Gobierno colombiano pueden tener repercusiones negativas en el ámbito del derecho internacional de inversiones. Novartis es una empresa suiza que puede invocar el TBPI entre Colombia y Suiza del 6 de octubre de 2006.

12 Ministerio de Salud y Protección Social. Resolución 2475 de 2016: "el tratamiento anual de un paciente con Glivec ${ }^{\circledR}$ cuesta $\$ 47540160$, mientras que el mismo tratamiento usando el medicamento competidor más barato del mercado cuesta $\$ 9234720$ (la diferencia es de $\$ 38305440$ al año)". 
La farmacéutica suiza Novartis puede ser considerada como un inversor extranjero (Art. 1 (2. b) TBPI Colombia-Suiza). Adicionalmente, según el artículo 1, numeral 1(d) del TBPI Colombia-Suiza, la patente del medicamento Imatinib tendría la protección de este tratado ya que explícitamente preceptúa: "El término "inversión" significa todo tipo de activo y particularmente: (d) Derechos de autor, derechos de propiedad industrial (como patentes, modelos de utilidad, modelos o diseños industriales $[\ldots])^{\prime \prime}$.

La cita de la norma anterior llevaría a concluir que la patente del medicamento desarrollado por Novartis merece protección y dado que al haberse declarado aquel como de interés público puede menoscabar las expectativas económicas del inversor extranjero. Por lo mencionado, la farmacéutica se encontraría legitimada para iniciar una demanda ante un tribunal de arbitramento ${ }^{13}$,pasada la etapa de solicitud de consultas.

Velásquez Ruíz (2016) sostiene que existen indicios que apuntarían a la intención de empezar un litigio por parte de Novartis. El primer indicio, es que el gobierno suizo a través de mecanismos diplomáticos intentó generar presiones con el propósito que Colombia no tomara la decisión de declarar el medicamento IMATINIB como de interés públi$\mathrm{CO}^{14}$. El segundo, es la continua litigiosidad en la que se ha visto envuelta la farmacéutica.

Entonces, tenemos una posibilidad de que la decisión sea demandada ante un tribunal de arbitraje internacional por una medida tomada por Colombia que pretende garantizar un derecho tan importante como es la salud pero que, sin embargo, según el Gobierno suizo puede ser expropiatoria y merma las expectativas económicas de un inversionista. Este caso nos sirve para evidenciar un caso en que los derechos legítimos de un inversionista privado se interponen con la obligación que tiene el Estado para la protección de los derechos de las personas.

Una salida que tiene Colombia la encontramos claramente en el protocolo que se entiende parte del TBPI y es la adición al artículo 6 . 
El aparte en mención trata los temas de expropiación y compensación, estableciendo que ninguno de los Estados firmantes podrá expropiar, nacionalizar o realizar cualquier otra acción que tenga los mismos efectos contra los inversionistas del otro Estado, a menos que dichas medidas se tomen con base en el interés público, de manera no discriminatoria, siguiendo el debido proceso y realizando una compensación pronta, efectiva y adecuada. A continuación, el artículo establece la forma en que se tasa la indemnización y los mecanismos legales que el inversionista tiene para realizar la revisión de la compensación dada por uno de los Estados parte del TBPI.

Seguidamente el Protocolo establece que el artículo 6 se debe entender sin perjuicio de la emisión de licencias obligatorias, otorgadas en relación con derechos de propiedad intelectual $\mathrm{u}$ otras medidas tomadas con base en el Convenio de la OMC sobre los Aspectos de los Derechos de Propiedad Intelectual relacionados con el Comercio (ADPIC). Respecto a Colombia, además, se entiende según el Protocolo que: 1) El criterio de "utilidad pública o interés social", contenido en el artículo 58 de la Constitución Política de Colombia es compatible con el término "Interés Público", utilizado en el artículo $6^{\circ}$ de este Convenio, y 2) El establecimiento de monopolios que priven a inversionistas de actividades económicas de Convenio con el artículo 336 de la Constitución Política de Colombia, deberá estar conforme con las obligaciones del artículo $6^{\circ}$ de este Convenio (Protocolo TBPI Colombia-Suiza, 17 de mayo de 2006).

Eventualmente, y ante una demanda, observamos que el mismo tratado preceptúa la posibilidad que Colombia o Suiza emitan licencias obligatorias en virtud del interés público. A raíz de lo mencionado, el tribunal de arbitramento debe tener en cuenta este aparte. Aunado a lo anterior, se debe considerar la obligación que tienen los Estados de proteger los derechos humanos y los árbitros deberían ponderar de una forma adecuada el derecho a la salud y la obligación que tiene el Estado en la consecución de este derecho que, para el caso en concreto, se manifestó en una medida tendiente a disminuir los precios y en consecuencia se puede generar una mayor asequibilidad a un medicamento y un alivio al presupuesto del Sistema General de Salud.

No debemos olvidar que las autoridades públicas deben tomar en serio su rol y estructurarse con base en el individuo que, en palabras 
prácticas, es dirigir su actividad en todas las direcciones creando una política verdaderamente incluyente, generando cohesión en una sociedad, respeto por los derechos y el ordenamiento, lo que tendrá por efecto el respeto y la legitimidad por las instituciones. Entonces, creemos que en verdad se debe realizar una reivindicación del rol de la persona, en cuanto a las instituciones, siendo necesario repensar algunas de ellas. Por lo tanto, no debe dejarse el ordenamiento de derechos humanos en una mera formalidad, sin llevarlo a la práctica.

Para esto se ha generado la idea del Ius Constitutionale Comnune en América Latina (ICCAL) como un mecanismo que tiene como objetivo el reforzamiento de la protección de los derechos humanos, el Estado de Derecho, la democracia, el Estado abierto y la construcción de organizaciones internacionales legítimas y eficaces. Esto según Von Bogdandy (2014) se puede alcanzar por medio del dialogo, la inclusión y el pluralismo normativo. Igualmente, el ICCAL según Von Bogdandy (2014) propone un diálogo entre las cortes nacionales e internacionales, esto se podría hacer extensivo a los tribunales de arbitramento y a las cortes nacionales y demás cortes internacionales, lo que tendría como resultado que el derecho económico de inversiones se acerque más a la protección del individuo y sus decisiones estén motivadas de acuerdo al derecho de inversiones y a los derechos humanos.

\section{Conclusión}

Los Estados en la actualidad han cedido su soberanía con el presunto fin de afrontar los retos que el mundo actual entraña. Como resultado de lo anterior se han establecido numerosos tratados en los que la finalidad única es darle relevancia al individuo respetando su dignidad ${ }^{15}$. También, se han creado organizaciones internacionales que garantizan que los Esta-

15 Como ejemplo se pueden enunciar Pacto Internacional de Derechos Económicos, Sociales y Culturales de 1976; el Pacto de Derechos civiles y políticos de 1966; el Convenio para la Protección de los Derechos Humanos y de las Libertades Fundamentales de 1950; la Convención sobre la eliminación de todas las formas de discriminación racial de 1965; la Convención sobre la tortura de 1985; la Convención sobre los Derechos del niño de 1989 y la Convención de las Naciones Unidas sobre diversidad biológica de 1992. 
dos cumplan todas estas normas. Sin embargo, el desplazamiento de los Estados no ha servido para satisfacer todas esas buenas intenciones que se consagran en los tratados, donde se protegen entre otros los derechos sociales, económicos y culturales.

Los Estados no han cumplido con su cuota en la materialización de un verdadero modelo de Estado social y democrático de Derecho, particularmente podemos hacer referencia a los países latinoamericanos y europeos como España. Los Estados consagran en sus ordenamientos constitucionales derechos y garantías, no obstante, aquellas no se materializan. Por lo tanto, y como sostiene (Salazar Ugarte, 2004) la positivación de los derechos no es razón para sostener la existencia de normas secundarias o políticas públicas que brinden garantías efectivas.

Del análisis realizado vemos que los intereses del mercado han arrebatado la centralidad de la persona y su dignidad como principio fundamentador del ordenamiento jurídico. En consecuencia, los derechos quedan desprotegidos, pero los derechos sociales más aun ya que necesitan la intervención del Estado, que cada vez más se ve influenciado por otro tipo de intereses que no se ajustan al general.

Ahora bien, debemos ser conscientes que el Estado debe adecuarse a las transformaciones de la sociedad, pero no a cualquier costo. Debe tener en todo momento clara su función y con esto realizar los procesos de cambio. De igual forma no se debe perder de vista que la satisfacción y la garantía de los derechos y las libertades de las personas no se alcanzan con la reducción sistemática a la que se está sometiendo al Estado. Por el contrario, lo ideal sería que en un Estado se salvaguardaran las prestaciones sociales, $y$, además el mercado coexistiera de forma pacífica y ayudara por medio de tributos a sostener al Estado.

También, para que exista una garantía de los derechos sociales y en general de los derechos humanos en el ámbito del derecho internacional de inversiones creemos que debe existir la incorporación de instrumentos al interior de los tratados, que permitan a los Estados la aplicación libre de políticas públicas a fin de crear una guarda real y efectiva de los derechos de las personas. También los árbitros, como autoridades públicas, deben tener en cuenta estos derechos a la hora de emitir sus laudos. No hablamos de privilegiar en todos los casos los intereses del Estado, pero sí debe existir un cierto sometimiento a los Derechos Humanos y a la 
garantía real y efectiva de los derechos sociales, económicos y culturales. Para ello nos mostramos de acuerdo con la incorporación de tribunales semi-permanentes en materia de derecho internacional de inversiones. Esto permitirá una mayor legitimidad y un verdadero diálogo entre cortes que tendrá como consecuencia una aplicación más real del ICCAL. De otro lado, al establecerse un tribunal permanente se puede generar de forma más rigurosa la rendición de cuentas de los jueces que fallan. Aunado a lo demás permite el seguimiento de precedentes, lo cual generará seguridad jurídica tanto para los Estados como para los inversores de manera conjunta.

Pero no todo recae sobre la comunidad internacional o sobre las Empresas. Los Estados deben crear en principio tratados más precisos que permitan establecer en qué casos se encuentran frente a una inversión. Por lo tanto, deben dejar de acudir a la clásica definición que inversión es "todo tipo de activo", al contrario, deben establecer claramente qué es una inversión y cuál es el trato que se le debe dar al inversionista, es decir, qué es un trato justo y equitativo, seguridad plena de las inversiones entre otros. Adicionalmente, y a fin que exista un real sometimiento a los derechos humanos, debe haber un apartado en los TBPI que los establezca y que permita la real y efectiva garantía de los mismos por parte de los Estados (adopción de políticas públicas) y de los inversores (responsabilidad social). Desde el principio se deben dejar claras las reglas para el inversionista.

De otro lado, los Estados deben generar transparencia, es decir, deben ser claros con las empresas extranjeras de las posibilidades y las complicaciones que puedan afectar una inversión. Piénsese, por ejemplo, en la explotación minera en una zona que posiblemente tiene importancia ecológica o que puede afectar a las comunidades indígenas o fuentes hídricas que sirven para la prestación del servicio de agua. La viabilidad de una inversión se deberá de hacer por medio del trabajo conjunto y coordinación de las entidades regionales, la comunidad y demás organizaciones interesadas (verbigracia, ONG). Lo descrito anteriormente redundará en que a futuro posiblemente exista una reducción de reclamos en virtud del derecho internacional de inversiones. 


\section{Referencias}

Abendroth, W. (1973). Sobre el concepto de estado de derecho democrático y social tal como se formula en la Constitución de la RFA. En W. Abendroth (Ed.), Sociedad antagónica y democracia política: ensayos sobre sociología política (p. 266-272). Barcelona: Grijalbo.

Almonacid Arellano y otros c. Chile (Corte Interamericana de Derechos Humanos, 26 de septiembre de 2006).

Alto Comisionado para los Derechos Humanos. (2003). Human rights, trade and investment. Report of the High Commissioner for Human Rights. [Version Digital Adobe Editions] Recuperado de http://www.ohchr.org/EN/Issues/ Globalization/Pages/ReportsHC.aspx

Balbuena Cisneros, A., Estrada, E., E Pisarello Prados, G. (2000). Estado de Derecho y crisis en América Latina: algunas notas entre la pesadilla y la esperanza. Alicante: Ediciones Universidad de Alicante.

Bazán, V. (2014). Vinculatoriedad de los estándares interpretativos de la Corte Interamericana de Derechos Humanos en los órdenes internos, control de convencionalidad y diálogo jurisprudencial. Anuario de Derecho Constitucional Latinoamericano, 20, 400.

Beck, U. (1998). ¿Qué es la globalización? (1. a ed.). Barcelona: Paidós.

Bohoslavsky, J., \& Bautista, J. (2011). Protección del derecho humano al agua y arbitrajes de inversión. CEPAL: Santiago de Chile.

Bohoslavsky, J., E Bautista, J. (2016). Compatibilizando derechos de los inversores extranjeros y derechos humanos: ¿Por qué? ¿Cómo? ¿Quién? ¿Cuándo? En A. Tanzi, A. Asteriti, P. Turrini \& R. Polanco Lazo (Eds.), International Investment Law in latin america: problems and prospects (1. ${ }^{\text {a }}$ ed., pp. 681-698). Holanda: Nijhoff international investment law series.

Carmona Cuenca, E. (2000). El estado social de Derecho en la constitución. Madrid: Consejo económico y social.

Cassese, S. (2002). El espacio jurídico global. Revista de Administración Pública, $157,12-26$.

Comunidad Indígena Sawhoyamaza c. Paraguay (Corte Interamericana de Derechos Humanos, 29 marzo de 2006).

Consejo de la Unión Europea. (2016). Propuesta relativa a la aplicación provisional del Acuerdo Económico y Comercial Global entre Canadá, por una parte, y la Unión Europea y sus Estados miembros. 
Las Palmeras c. Colombia (Corte Interamericana de Derechos Humanos, 6 de diciembre de 2001).

De Cabo, C. (2006). Teoría constitucional de la solidaridad. Barcelona: Marcial Pons.

De Cabo, C. (diciembre, 2014). El común como elemento constituyente. Ponencia presentada en el III Congreso Teoría y Práctica del Poder Constituyente, Universidad de Valencia, Valencia.

De Lucas, J. (1998). La globalización no significa universalidad de los derechos humanos: en el 50 aniversario de la Declaración del 48. Jueces Para La Democracia, 32, 3-9.

De Vergottini, G. (2004). Derecho constitucional comparado. Mexico: Universidad Autónoma de México.

Dupuy, P.-M. (2011). Unification rather fragmentation of international law? The case of international investment and human rights law. En P.-M. Dupuy \& F. Francioni (Eds.), Human Rights in International Investment Law and Arbitration

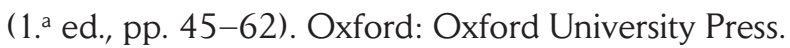

Eco Oro Minerals Corp. c. República de Colombia (Internacional Centre of Settlement of Investment Disputes, fallo pendiente, 29 de diciembre de 2016)

Fernández, F. (2013). Arbitraje inversor-Estado: de "bella durmiente" a "león en la jungla". Revista Electrónica de Estudios Internacionales, 26, 4-27.

Fernández, J. C. (2009). América Latina y el arbitraje de inversiones: ¿matrimonio de amor o matrimonio de conveniencia? Revista de La Corte Española de Arbitraje, XXIV, 13-37.

Forsthoff, E. (1886). Concepto y esencia del Estado social de Derecho. En W. Abendroth (Ed.), El Estado social (1. ${ }^{\text {a }}$ ed., pp. 93-97). Madrid: Centro de estudios constitucionales.

García Pelayo, M. (1989). Las transformaciones del Estado contemporáneo. Madrid. Madrid: Alianza.

Garrido Baigorria c Argentina (Corte Interamericana de Derechos Humanos, 27 de agosto de 1998).

Gelman c. Uruguay (Corte Interamericana de Derechos Humanos, 24 de febrero de 2011).

Gelman c. Uruguay, resolución de cumplimiento de caso (Corte Interamericana de Derechos Humanos, 20 de marzo de 2013).

Gros, H. (2003). La dignidad humana en los instrumentos internacionales sobre derechos humanos. Nueva Época, 4, 193-223.

Häberle, P. (2008). La dignidad del hombre como fundamento de la comunidad estatal en el derecho alemán. En F. Fernández Segado (Ed.), Dignidad de 
la persona, derechos fundamentales, justicia constitucional (p. 197-210) España: Dykinson.

Jacob, M. (2010). International investment agreements and Human Rights. Duisburgo: Institute for Development and Peace $\mathcal{E}$ Universidad de Essen.

Knoll-Tudor, I. (2009). The fair and equitable treatment Standardas and Human Rights norms. In P.-M. Dupuy \& E.-U. Petersmann (Eds.), Human Rights in International Investment Law and Arbitration (1. ${ }^{\mathrm{a}}$ ed., pp. 336-338). Oxford: Oxford University Press.

Koskenniem, M. (2006). Fragmentation of international law: Dificulties arising from the diversification and expansion of international law. [Versión Digital Adobe Editions] Recuperado de http://legal.un.org/ilc/documentation/english/a cn4_1682.pdf

Lee, J. (2013). UNCITRAL's Unclear Transparency Instrument: Fashioning the Form and Application of a Legal Standard Ensuring Greater Disclosure in Investor-State Arbitrations. Northwestern Journal of International Law \& Business, 33, 447-473.

León Alomso, M. (2009). La protección constitucional de la salud en el marco del Estado social y democrático de Derecho (1. a ed.). Salamanca: Ediciones Universidad de Salamanca.

Leturia, F. (2016). La contribución al desarrollo del Estado Receptor como requisito de la noción de inversión: La experiencia de los países latinoamericanos. En A. Tanzi, A. Asteriti, P. Turrini \& R. Polanco Lazo (Eds.), International Investment Law in latin america: problems and prospects (1. ${ }^{\text {a }}$ ed., p. 275-303. Holanda: Nijhoff international investment law series.

López-Ayllón, S. (1997). The impact of Globalization on the reform of the State and Law in Latin America. Houston Journal of International Law, 3, 786-798. Mir, O. (2004). Globalización, Estado y Derecho: Las transformaciones recientes del derecho administrativo (1.a ed.). Madrid: Thomson.

Monereo, J. (2014). Derecho a la salud. En J. Monereo Pérez \& C. Monereo Atienza (Eds.), El sistema universal de los derechos humano (p. 595-605). Granada: Comenares.

Morales, M. (2014). El nuevo paradigma de la apertura de los órdenes constitucionales: una perspectiva sudamericana. En A. Von Bogdandy \& J. M. Serna de la Garza (Eds.), Soberanía y Estado abierto en América Latina y Europa (p. 234-238). Mexico: Instituto de investigaciones jurídicas.

Navarro, P. (2016). El nuevo derecho administrativo global como lex administrativa en el arbitraje internacional de inversiones.Revista General de Derecho 
Administrativo, (42). Recuperado de http://www.iustel.com/v2/revistas/ detalle_revista.asp?id_noticia $=417477 \mathrm{Gd}=1$

Observación general 14 (2000). Comité De Derechos Económicos, Sociales Y Culturales.

Peces, G. (2003). La dignidad de la persona desde la filosofía del Derecho (1. a ed.). Madrid: Dykinson.

Petersmann, E.-U. (2009). Introducction and summary: Administration of justice in international Invesment law and adjudication. En P.-M. Dupuy \& F. Francioni (Eds.), Human Rights in International Investment Law and Arbitration (1. ${ }^{\text {a }}$ ed., pp. 12-15). Oxford: Oxford University Press.

Pisarello, G. (2000). Globalización, mundialización y crisis del concepto de soberanía. En A. De Cabo de la Vega \& G. Pisarello Prados (Eds.), Globalización, mundialización y crisis del concepto de soberanía: algunos efectos en América Latina y en Europa (pp. 25-30). Alicante: Ediciones Universidad de Alicante.

Polanco, R. (2016). Two worlds apart: The changing features of international investment agreements in Latin America. En A. Tanzi, A. Asteriti, P. Turrini \& R. Polanco Lazo (Eds.), International Investment Law in latin america: problems and prospects ( $1 .^{\text {a }}$ ed., pp. 76-79). Holanda: Nijhoff international investment law series.

Pozzi, S. (30 de septiembre de 2016). 10 empresas más grandes que 180 países. El País. Recuperado de http://economia.elpais.com/economia/2016/09/29/ actualidad/1475150102_454818.html

Prieto, E. (2011). BIT y la Constitución Colombiana de 1991 : internacionalización de la economía dentro de un Estado social de Derecho. Estudios Socio Jurídicos, 13(1), 109-143.

Prieto, E., E Urueña, R. (2016). ¿Vino viejo, botellas nuevas? A propósito del Acuerdo Económico y Comercial Global (CETA) entre Canadá y la Unión Europea. Revista de Derecho Económico Internacional, 17, 8-24.

Prieto, J. (2016). International Investment Disputes in South America: Rethinking Legitimacy in the context of global pluralism. En A. Tanzi, A. Asteriti, P. Turrini, \& R. Polanco Lazo (Eds.), International Investment Law in latin america: problems and prospects (1. ${ }^{\text {a }}$ ed., pp. 137-157). Holanda: Nijhoff international investment law series.

Salazar, P. (2004). Disputa por los derechos y el ius constitutionale commune. En H. Fix Fierro \& M. Morales Antoniazzi (Eds.), Ius constitutionale commune en América Latina: rasgos, potencialidades y desafios (1. a ed., pp. 40-60). Mexico: Universidad Autónoma de México. 
Schill, S. (2016). International investment law and public comparative law in latin american perspective. In A. Tanzi, A. Asteriti, P. Turrini, \& R. Polanco Lazo (Eds.), International Investment Law in latin america: problems and prospects (1. a ed., pp. 44-52). Holanda: Nijhoff international investment law series.

Schreuer, C., E Reiner, C. (2011). Human rights and international investment arbitration. En P.-M. Dupuy, \& F. Francioni (Eds.), Human Rights in Interna-

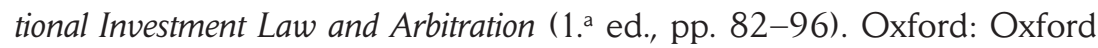
University Press.

Serna, J. M. (2014). Soberanía y apertura del Estado: una perspectiva mexicana. En A. Von Bogdandy \& J. M. Serna de la Garza (Eds.), Soberanía y Estado abierto en América Latina y Europa (pp. 1-60). Mexico: Instituto de investigaciones jurídicas.

Sin autor. (31 de marzo de 2016). El club de la pelea: Ola de demandas contra Colombia. Revista Dinero. Recuperado de http://www.dinero.com/edicionimpresa/caratula/articulo/la-polemica-fronteriza-con-nicaragua-y-otrasdemandas-que-colombia-enfrenta/221885

Sin autor. (5 de octubre de 2016). Gas Natural reclama 1100 millones al Gobierno colombiano por impagos. El País. Recuperado de http://economia. elpais.com/economia/2016/10/05/actualidad/1475699407_403309.html

Solórzano, J. F. (2016). La asistencia jurídica pública al Estado y su influencia en la actuación del poder Ejecutivo (1. a ed.). Salamanca: Ediciones Universidad de Salamanca.

Torres, A. (2012). Principios fundamentales del poder público globalizado. En A. Von Bogdandy \& J. M. Serna de la Garza (Eds.), Soberanía y Estado abierto en América Latina y Europa (p. 121-138). Mexico: Instituto de investigaciones jurídicas.

Naciones Unidas. (2016). World Investment Report. [Versión Digital Adobe Editions] Recuperado de http://unctad.org/en/pages/PublicationWebflyer. aspx?publicationid $=1555$

Van Harten, G. (julio, 2008). A case for an international investment court. Conferencia inagural de la Sociedad de Ley Económica Internacional, Genova.

Van Harten, G. (2010). Investment Treaty Arbitration, Procedural Fairness, and the Rule of Law. En S. Stephan (Ed.), International Investment and Comparative Law (pp. 643-654). Oxford: Oxford University Press.

Velásquez, M. (14 de marzo de 2016). ¿Y si Novartis demanda a Colombia? El Espectador. Recuperado de http://www.elespectador.com/noticias/salud/ysi-novartis-demanda-colombia-articulo-622083 
Von Bogdandy, A. (2011). La protección de los vulnerables: un ejemplo de gobernanza posnacional. En A. Von Bogdandy, H. Fix-Fierro, \& M. Morales Antoniazzi (Eds.), Construcción y papel de los derechos sociales fundamentales

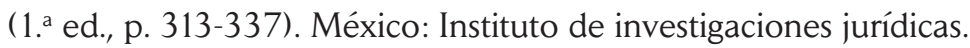

Von Bogdandy, A. (2014). Los principios fundamentales después de la apertura del Estado: un estudio desde la perspectiva alemana. En A. Von Bogdandy, E J. Serna de la Garza (Eds.), Soberanía y Estado abierto en América Latina y

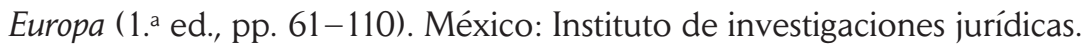

Von Bogdandy, A., \& Venzke, I. (2011). Beyond Dispute: International Judicial Institutions as Lawmakers. German Law Journal, 12, 981-1003.

Von Bogdandy, A., E Venzke, I. (2013). ¿En nombre de quién? En E. Ferrer Mac gregor \& A. Herrera García (Eds.), Diálogo jurisprudencial en Derechos Humanos: entre tribunales constitucionales y cortes internacionales (1. ${ }^{\text {a }}$ ed., p. 111-120). Valencia: Tirant lo Blanch.

Von Bogdandy, A., E Venzke, I. (2016). ¿En nombre de quién? Una teoría de derecho público sobre la actividad judicial internacional (1. a ed.). Bogotá: Universidad Esternado de Colombia.

Zamora, S. (1997). Allocating legislative competence in the Americas: the early experience under NAFTA and the challenge of hemispheric integration. Houston Journal of International Law, 3, 762-780. 


\section{RESEÑAS}

TONGE, J. (2014). COMPARATIVE PEACE PROCESSES. POLITY PRESS

Natalia Abril

CAJAS SARRIA, M. A. (2015) LA HISTORIA DE LA CORTE SUPREMA DE JUSTICIA DE COLOMBIA, 1886-1991. TOMO I: DE LA REGENERACIÓN AL RÉGIMEN MILITAR, 1886-1958. 409 P. TOMO II: DEL FRENTE NACIONAL A

LA ASAMBLEA CONSTITUYENTE, 1958-1991. 451 P. UNIVERSIDAD

DE LOS ANDES, UNIVERSIDAD ICESI, COLECCIÓN HISTORIA Y MATERIALES

DEL DERECHO

Michael Cruz Rodríguez

ANTONIO JOSÉ RENGIFO LOZANO. (2011). INTERNATIONAL REGIME THEORY

AND THE LAW OF THE SEA: A STUDY OF FISHERIES ON THE HIGH SEAS. BOGOTÁ: EDITORIAL UNIVERSIDAD NACIONAL DE COLOMBIA

Ana Lucía Rodríguez 